\title{
The Leaf Bacterial Microbiota of Female and Male Kiwifruit Plants in Distinct Seasons: Assessing the Impact of Pseudomonas syringae pv. actinidiae
}

\author{
Aitana Ares, ${ }^{1,2}$ Joana Pereira, ${ }^{1}$ Eva Garcia,,${ }^{1,2}$ Joana Costa, ${ }^{1,2, \dagger}$ and Igor Tiago ${ }^{1, \dagger}$ \\ ${ }^{1}$ University of Coimbra, Centre for Functional Ecology, Department of Life Sciences, Calçada Martim de Freitas, $3000-456$ Coimbra, \\ Portugal \\ ${ }^{2}$ FitoLab, Laboratory for Phytopathology, Instituto Pedro Nunes, 3030-199 Coimbra, Portugal
}

Accepted for publication 21 April 2021.

\begin{tabular}{|c|c|}
\hline \multicolumn{2}{|c|}{ ABSTRACT } \\
\hline $\begin{array}{l}\text { The Pseudomonas syringae pv. actinidiae pandemic has } \\
\text { been compromising the production of the kiwifruit industry in } \\
\text { major producing countries. Abiotic factors and plant gender are } \\
\text { known to influence the disease outcome. To better understand } \\
\text { their impact, we have determined the diversity of the leaf } \\
\text { bacterial communities using the V5-V6 region of the } 16 S \text { ribo- } \\
\text { somal RNA gene amplicon on the Illumina MiSeq sequencing } \\
\text { platform. Healthy and diseased female and male kiwifruit plants } \\
\text { were analyzed in two consecutive seasons: spring and autumn. } \\
\text { This work describes whether the season, plant gender, and } \\
\text { presence of } P \text {. syringae pv. actinidiae can affect the leaf bacte- } \\
\text { rial community. Fifty bacterial operational taxonomic units were } \\
\text { identified and assigned to five phyla distributed by } 14 \text { different } \\
\text { families and } 23 \text { genera. The leaves of healthy female and male } \\
\text { kiwi plants share most of the identified bacterial populations, } \\
\text { which undergo major seasonal changes. In both cases, a }\end{array}$ & $\begin{array}{l}\text { substantial increase of the relative abundance of genus Methyl- } \\
\text { obacterium is observed in autumn. The presence of } P \text {. syringae } \\
\text { pv. actinidiae induced profound changes on leaf bacterial com- } \\
\text { munity structures, translated into a reduction in the relative } \\
\text { abundance of previously dominant genera that had been found } \\
\text { in healthy plants; namely, Hymenobacter, Sphingomonas, and } \\
\text { Massilia spp. The impact of } P \text {. syringae pv. actinidiae was less } \\
\text { pronounced in the bacterial community structure of male plants } \\
\text { in both seasons. Some of the naturally occurring genera have } \\
\text { the potential to act as antagonists or as enhancers of the } \\
\text { defense mechanisms, paving the way for environmentally } \\
\text { friendly and sustainable disease control. } \\
\text { Keywords: Actinidia chinensis var. deliciosa, Illumina MiSeq } \\
\text { sequencing, leaf bacterial biocoenosis, Pseudomonas syringae } \\
\text { pv. actinidiae, structural diversity }\end{array}$ \\
\hline
\end{tabular}

†Corresponding authors: J. Costa; jcosta@uc.pt; and I. Tiago; itiago@uc.pt

Funding: This work was supported by the Community Initiative Action 1.1 Operational Groups "I9K-InovKiwi-Development of strategies for the sustainability of the kiwifruit sector through the creation of a value-added product" promoted by PDR2020 and co-financed by the FEADER under the Portugal 2020 Partnership Agreement. A. Ares acknowledges financial support by postdoctoral grants from FCT/MEC through national funds and the cofunding by the FEDER, within the PT2020 Partnership Agreement, and COMPETE 2020, within the project UID/BIA/04004/2013. I. Tiago acknowledges an Investigator contract, reference IF/01061/2014.

*The $e$-Xtra logo stands for "electronic extra" and indicates that a supplementary figure and supplementary tables are published online.

The author(s) declare no conflict of interest.

This article is in the public domain and not copyrightable. It may be freely reprinted with customary crediting of the source. The American Phytopathological Society, 2021.
There are four cultivable species of Actinidia-A. chinensis, A. arguta, A. kolomikta, and A. eriantha-but the first leads the international kiwifruit production. Although A. chinensis var. chinensis has recently been introduced as a cash crop arousing great interest, A. chinensis var. deliciosa is still the main variety in production (Guroo et al. 2017). Within this variety, the cultivar Hayward currently dominates international kiwifruit orchards. Most of the species of genus Actinidia are dioecious plants, with female and male plants displaying distinct behaviors; namely, distinct susceptibility to diseases and differentiated phenological development stages (EPPO 2012; Wang and Gleave 2012). Kiwifruit orchards are composed mainly of female plants intercalated with a few male kiwifruit vines, the latter required mainly for pollination (Ferguson et al. 1996). Moreover, the bacterial populations present in the leaves are known to influence their susceptibility to pathogens as well as the fate of the infection (Afzal et al. 2019; Araújo et al. 2002; Lamichhane and Venturi 2015; Liu et al. 2017; Straub et al. 2018; Vorholt 2012). In this context, some microorganisms are known to stimulate the plant immune system (Pieterse et al. 2012), 
suppressing pathogen proliferation by inducing rapid death of the host cells in the infection site (Buonaurio et al. 2015; Innerebner et al. 2011).

Pseudomonas syringae pv. actinidiae is the causal agent of kiwifruit bacterial canker, considered the most serious and important disease reported for this crop (Donati et al. 2014; Straub et al. 2018; Vanneste 2017). Blossom blight caused by $P$. viridiflava and $P$. syringae pv. syringae is another disease that affects Actinidia spp. This disease has a restricted distribution in the plant, affecting leaves and blossoms that may wither before opening or fall off soon after fruit set, with relevant economic impacts (Balestra et al. 2008; González et al. 2003). Different strategies have been tested to control the pandemic caused by $P$. syringae pv. actinidiae: preventive agronomic practices, chemical control with copper products, antibiotics and the use of resistance inducers (Do et al. 2016; Mauri et al. 2016; Monchiero et al. 2014); nevertheless, none is a curative method. In addition, some of these strategies cause side effects such as phytotoxicity or bacterial resistance and leave unwanted residues in fruit (Cameron and Sarojini 2014; Donati et al. 2014). Currently, environmental and food safety are growing concerns for the consumer society, increasing the demand for safe alternatives to the chemical control of phytopathogens (Mari et al. 2015; Pal and Gardener 2006).

In line with sustainable agriculture, the selection of microbial isolates naturally present in microbiota of plants has been used as a biocontrol against plant diseases with different modes of action (Berg and Koskella 2018; Köhl et al. 2019). Recent studies demonstrated that $P$. synxantha, Lactobacillus plantarum, $P$. putida biotype A, P. fluorescens, P. mendocina, Kluyvera intermedia, Pantoea aglomerans, or Bacillus amyloliquefaciens subsp. plantarum isolated from Actinidia sp. presented promising characteristics as biocontrol agents against Pseudomonas syringae pv. actinidiae (Balestra et al. 2014; Buriani et al. 2018; Tontou et al. 2015, 2016). Furthermore, Wicaksono et al. (2018) demonstrated that bacteria isolated from Leptospermum scoparium (tea tree) could control P. syringae pv. actinidiae in vitro.

Advances in next-generation sequencing (NGS) technology have made it possible to determine the structure and predict the function of the microbiota of crops and model plants; namely, in Oryza sativa, Zea mays, Olea europea, Malus domestica, Vitis vinifera, Arabidopsis thaliana, and Rubus idaeus (Busby et al. 2017; Liu et al. 2018; Perpetuini et al. 2019; Pinto et al. 2014; Yashiro et al. 2011). This innovative approach allows the identification of taxonomic groups of naturally occurring bacteria that could, in the future, be isolated and tested for their potential use as an antagonist or as enhancers of the defense mechanisms in plants against pathogens (Berg et al. 2017). Strategies that involve the enhancement of plant microbiota will have an even greater impact on production yield in regions of the world with low soil fertility and water availability, as well as those most affected by diseases (Sessitsch and Mitter 2015; Toju et al. 2018).

Several factors are known to shape microbial communities, resulting in a panoply of ecological niches. In this context, host plant genotype, plant species or cultivar, and plant organ and plant health status can influence the microbiota structure and diversity (Arrigoni et al. 2018; Purahong et al. 2018; Turner et al. 2013). In addition, the geographical location and soil type can directly affect the microbiota diversity (Berg et al. 2016; Liu et al. 2017; Wagner et al. 2016). Anthropogenic factors such as management agricultural practices, the addition of fertilizers, or farming systems that alter the biotic and abiotic properties of the soils cause strong effects on the bacterial community composition (Busby et al. 2017).

Few studies describe the Actinidia sp.-associated bacterial community. Recently, the kiwifruit pollen microbiota was analyzed and
Proteobacteria followed by Actinobacteria and Firmicutes were the most abundant bacterial phyla described (Kim et al. 2018). Also, the phyllosphere bacterial communities from kiwifruit plants infected with $P$. syringae pv. actinidiae were assessed, identifying Proteobacteria, Firmicutes, Actinobacteria, and Bacteroidetes as the phyla most represented from a total of 16 genera, altogether comprising 220 genera (Purahong et al. 2018). Surprisingly, the most abundant operational taxonomic unit (OTU) was classified as Pseudomonas, indicating the ubiquity of this genus in this plant microbiota (Purahong et al. 2018). Nevertheless, studies about bacterial communities cannot be extrapolated, because the microbiota may vary from place to place and over time (Berg et al. 2016).

The main objective of this study was to characterize the bacterial structural diversity present in the leaves of Actinidia chinensis var. deliciosa and to determine how different variables alter these communities. To tackle this problem, we investigated whether the reported difference in the susceptibility to $P$. syringae pv. actinidiae between female and male plants of A. chinensis var. deliciosa 'Hayward' (Donati et al. 2020) translates into distinct associated leaf bacterial communities. In addition, the analysis was performed on two distinct occasions, allowing to determine how environmental factors (important for the survival of $P$. syringae pv. actinidiae) influenced the bacterial community structure.

Every man-made system (such as managed agriculture systems) includes the adoption of practices that induce a profound impact on the bacterial community composition (Busby et al. 2017). For these reasons, this study was conducted in two neighboring kiwifruit orchards with no human intervention in that year (one with $P$. syringae pv. actinidiae present and the other free of $P$. syringae pv. actinidiae), providing us with the opportunity to study microbial populations that have been modulated solely by environmental factors rather than by human activities. Our study serves as a baseline for the identification of bacterial groups with potential antagonist capability or with a potential role in the modulation of kiwifruit canker.

\section{MATERIALS AND METHODS}

Description of the analyzed $A$. chinensis var. deliciosa orchards. Leaves were collected from A. chinensis var. deliciosa 'Hayward' and 'Tomuri' from two neighboring organic kiwifruit orchards in

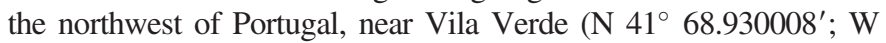
$8^{\circ} 4079839^{\prime}$ ) (Supplementary Fig. S1). Vines were trained on a T-bar support system with spacing of $5 \mathrm{~m}$ between rows and an interplant distance within rows of $2.5 \mathrm{~m}$. Males were found next to the posts in a ratio of one male to eight females. In the 2 years preceding sampling, no chemical control with copper products, no fertilization, and no commercial pollen was applied in these orchards. The only agronomic practices performed were orchard pruning, cutting grass, and harvesting.

Both orchards were tested for the presence of $P$. syringae pv. actinidiae according to EPPO standards (EPPO 2014) for 2 years before sampling, and after sampling. For each sample (described below), the presence or absence of $P$. syringae pv. actinidiae was determined according to Gallelli et al. (2011).

From now on, we will refer to the orchards as healthy $(\mathrm{H}=$ no $P$. syringae pv. actinidiae detected) and diseased $(\mathrm{D}=P$. syringae pv. actinidiae detected). The $\mathrm{H}$ orchard was 30 years old with an area of 0.5 ha and the D orchard was planted in 2011 with an area of 1 ha. During the time course of the experiment, the severity of the disease in orchard D was low but the incidence was $50 \%$, following the average disease incidence and virulence in the previous season.

Sampling and processing. Five female and five male plants were selected from each orchard, and 10 leaves from each plant were handpicked and combined to make a composite sample by 
gender. Leaves had approximately the same size and were collected in different cardinal orientations and locations: top, down, inner, and outer. In the case of infected plants, leaves exhibiting clear visual symptoms (i.e., necrotic leaf spots surrounded by yellow haloes) associated with Pseudomonas spp. diseases were selected. The sampling procedure was performed on two distinct occasions from the same trees: in June (after bloom, spring; reflecting the bacterial communities' response to spring and early summer environments) and in October (autumn environment; reflecting the bacterial communities' response to summer and early autumn abiotic conditions). Leaves were placed in sterile bags, labeled, and kept at $4^{\circ} \mathrm{C}$ and processed in the laboratory on the same day. In total, eight composite samples were obtained, four collected in spring and four in autumn, from healthy males (HM), healthy females (HF), diseased males (DM), and diseased females (DF). From each batch, $150 \mathrm{~g}$ of leaves was homogenized in a blender with $600 \mathrm{ml}$ of Milli-Q water sterile water (filtered through $0.1-\mu \mathrm{m}$ Millipore polycarbonate filters (47 $\mathrm{mm}$ in diameter) and autoclaved).

DNA extraction from A. chinensis var. deliciosa leaves. For each batch, the total genomic DNA was extracted from $5 \mathrm{~g}$ of leaf homogenate with a PowerMax Soil DNA Isolation Kit (MoBio Laboratories, USA). All steps were carried out according to the manufacturer's protocol, except with an additional cleaning step, involving homogenization with chloroform/isoamyl alcohol solution (24:1; vol/vol), centrifuging for $10 \mathrm{~min}$ and recovery of the upper aqueous phase, before the addition of the solution C4. DNA concentration and purity were assessed with NanoDrop ND-1000 spectrophotometer (Thermo Fisher Scientific).

Bacterial 16S ribosomal RNA gene amplification. To verify the integrity of the genomic DNA, for each sample, the $16 \mathrm{~S}$ ribosomal RNA (rRNA) gene was amplified by PCR using universal primers for Bacteria domain: 27F (5'-GAGTTTGATCCTGGCT CAG-3') and 1525R (5'-AGAAAGGAGGTGATCCAGCC-3'), as previously described (Rainey et al. 1996). PCR products were separated by electrophoresis on a $2 \%$ agarose gel in $0.5 \times$ Tris-borateEDTA buffer. A molecular marker (NZYDNA Ladder III, 200 a, 1,000 bp; Nzytec) was used for comparison purposes with a UV transilluminator (Molecular Imager Gel Doc XR+; Bio-Rad).

Illumina sequencing and data analysis. The structural diversity of the bacterial communities was inferred from the 16S rRNA gene sequence determined with Illumina's MiSeq platform. Primers 799F-mod3 CMGGATTAGATACCCKGG (Hanshew et al. 2013) and modified 1115R AGGGTTGCGCTCGTTG (Kembel et al. 2014) covering regions V5 to V6 were used because they were previously described as reducing plastid contamination (Chelius and Triplett 2001). Metabarcoding raw data were analyzed by using mothur v.1.41.1 (http://www.mothur.org) (Schloss et al. 2009). Briefly, sequences were subjected to conservative quality-control measures; namely, initial quality trimming and assembly of contig read sequences. Through the analysis workflow, all sequence reads with low quality, a high number of ambiguous bases, and chimeras were removed from the data sets. High-quality sequences were aligned, clustered into OTUs at a cut off of $97 \%$ sequence similarity, and phylogenetically classified using the ARB-Silva taxonomic database file silva.nr_v132.tax (https://www.arb-silva.de/). Finally, OTUs with $<1 \%$ relative total abundance were removed. The OTU data, with bacterial taxonomic and bacterial relative abundance data in each sample, are provided in Supplementary Table S1. Raw sequence data were deposited in the Sequence Read Archive database at NCBI under BioProject accession number PRJNA665460.

Diversity indexes and statistical analysis. Similarity percentages (SIMPER) analysis was calculated with PAST 3.0 (Hammer et al. 2001) to determine the identity, average dissimilarity, and relative abundance of the bacterial taxa that contributed most to the observed pairwise variation in the bacterial community composition due to different kiwifruit plant species (female versus male healthy plants), abiotic factors (spring versus autumn in healthy plants), and the presence of $P$. syringae pv. actinidiae (healthy versus diseased plants).

The dendrogram of the bacterial community structure was created using the unweighted pair-group method with arithmetic means (UPGMA) and similarity index Bray-Curtis. Cluster analysis of the samples was performed in PRIMER v6 software using the UPGMA (group average method) on the rarefied OTU table to construct a Bray-Curtis distance matrix.

Generalized linear models (GLMs) (R package glm) were used to predict the relationships between the abundance of each genus (response variable) and the environmental variables season (spring and autumn), health status ( $P$. syringae pv. actinidiae not detected $=$ healthy and $P$. syringae pv. actinidiae detected $=$ diseased), and gender (female and male). $P$ values $<0.05$ were considered statistically significant. Multiple comparisons were performed with Fisher's least significant difference to determine which means were significantly different. All analyses were run on R 4.0.1. To compare the samples, the Kruskal-Wallis test was used as a nonparametric approach.

A principal component analysis (PCA)-interspecies correlation was constructed based on the taxonomy results obtained at genus level to display the clustering of samples with software package PAST 3.0 (Hammer et al. 2001).

The $\alpha$ - and $\beta$-diversity indexes were calculated with the $\mathrm{R}$ package vegan. $\alpha$-Diversity analyses were measured with Shannon, Simpson reciprocal, and Pielou indices. $\beta$-Diversity was measured with the Jaccard index (Jaccard 1912) to compare the diversity obtained for both genders and determine the percentage of shared taxa. A linear discriminant analysis (LDA) effect size (LEfSe) method was used to determine whether the analyzed variables induced significant differences in the abundance of each taxon. The analysis was performed in the online Galaxy version 1.0 interface (The Huttenhower Lab 2018), with the threshold for the logarithmic LDA score was set at 2.0 and the Wilcoxon $P$ value at 0.05 .

\section{RESULTS AND DISCUSSION}

The bacterial microbiota of $A$. chinensis var. deliciosa leaves. The sequences obtained from NGS were grouped into 50 bacterial OTUs. The level of sequencing coverage varied between 98.6 and 99.9\% (Table 1), meaning that the OTUs recovered in this study represented nearly the whole bacterial genetic diversity, supporting a robust analysis.

A total of five phyla, seven classes, 12 orders, 14 families, and 23 genera were retrieved (Supplementary Table S1). The dominant phylum was Proteobacteria (76.9\%), with classes Alphaproteobacteria and Gammaproteobacteria as the most represented, with 48.4 and $28.1 \%$, respectively. Similar results were reported by other authors in the phyllosphere of Actinidia (Purahong et al. 2018) and on the leaves from other plants species (Whipps et al. 2008). Other abundant phyla were Bacteroidetes (13\% of the total diversity), followed by Actinobacteria (1.6\%), Deinococcus-Thermus (0.4\%), and Firmicutes $(0.3 \%$ ) (Fig. 1A). At the genus level, Sphingomonas (21.7\%), Pseudomonas (20.8\%), Hymenobacter (20\%), and Methylobacterium (17.8\%) were the most abundant, accounting for approximately $80 \%$ of the total diversity (Fig. 1B). All genera were shared by at least four samples; nevertheless, $22 \%$ of these bacterial taxa were rare because each represented $<1 \%$ of the total diversity (Supplementary Table S1).

Genera Methylobacterium and Sphingomonas have been reported several times in association with the phyllosphere (Innerebner et al. 2011; Vandenkoornhuyse et al. 2015) and as dominant on the fruit 
of $R$. idaeus but also as bacterial endophytes; for example, Methylobacterium extorquens in citrus plants (Araújo et al. 2002) and Sphingomonas paucimobilis in rice (Engelhard et al. 2000). Additionally, genus Hymenobacter has been found as an endophytic bacterium on leaves of several plant species (Aydogan et al. 2018) and, in Paulownia spp., represents the core phyllosphere microbiome although the function is still unknown (Woźniak et al. 2018). Nevertheless, the presence of this genus here described may differ from previous studies (Purahong et al. 2018), most probably because the endophytic community was excluded from them.

The GLM, used with the relative abundance of each genus and the predictive factors gender (male and female plants), healthy status (detection and non-detection of $P$. syringae pv. actinidiae) and season (spring and autumn), was not statistically significant because the $P$ value $>0.05(F=2.4 ; P=0.06)$ with a $95.0 \%$ confidence level.

Effect of $P$. syringae pv. actinidiae infection on the bacterial community of $A$. chinensis var. deliciosa leaves. Although no precise quantification of $P$. syringae pv. actinidiae was made, our results showed that the bacterial communities of kiwifruit leaves infected with $P$. syringae pv. actinidiae were profoundly affected, leading to a meaningful reduction in population diversity and evenness (Tables 2 and 3). The LEfSe identified bacterial taxa statistically different between healthy and diseased plants (Fig. 2). Genera Pseudomonas, Methylobacterium, Hymenobacter, Sphingomonas, 1174-901-12 (Rhizobiales), Massilia, and Novosphingobium were the taxa that contributed the most to the observed pairwise variation in the bacterial community composition (Supplementary Table S1). Overall, in the presence of $P$. syringae pv. actinidiae, an increase in the relative abundance of the phylum Proteobacteria was notorious and, in parallel, a decrease in the relative abundance of phyla Bacteroidetes and Actinobacteria was observed (Fig. 1A). The highest impact caused by $P$. syringae pv. actinidiae infection was observed on the bacterial community of leaves of female plants during spring, with an overall average dissimilarity between healthy and disease plants of $92.7 \%$ (Tables 2 and 3). A similar tendency, although not so evident, was observed in the autumn, with an overall average dissimilarity between healthy and disease female plants of $49.9 \%$ (Tables 2 and 3 ).

The impact of $P$. syringae pv. actinidiae infection was less pronounced in the bacterial communities of male plants in both seasons, perceivable by the overall average dissimilarity values between healthy and diseased plants of 64.1 and $43.4 \%$, in spring and autumn, respectively (Tables 2 and 3). This effect was more discrete in autumn, similar to what was observed for female plants. The clusterbased analysis indicated the described impact of $P$. syringae pv. actinidiae infection by clustering diseased plants (Fig. 1B).
Despite the infection, female and male plant samples were grouped by season, indicating its importance as a factor shaping bacterial microbiota, coinciding with the results presented by Giampetruzzi et al. (2020). These results were supported by the $\operatorname{GLM}(F=1.87 ; P=0.17)$ and later corroborated by the KruskalWallis test $(P=0.971)$ because only season was considered statistically significant by both analyses. The $P$ value and the statistics of the pairwise comparisons of the samples for each health status in each season for both female and male plants is shown in Supplementary Table S2. P. syringae pv. actinidiae infection translated into changes in the bacterial population relative abundances, which were particularly noticeable in spring, with a huge decrease in the total diversity by the emergence of Pseudomonas as the dominant genus (Fig. 3A). During this season, genus Pseudomonas increased 22 and 119 times, accounting for 97.1 and $61.9 \%$ of the overall diversity in infected female and male plants, respectively, when compared with the healthy counterparts (Fig. 3A). A more comprehensive comparison of the taxa distribution between healthy and diseased plants indicated the strong impact of $P$. syringae pv. actinidiae infection linked to a profound shift in the shared bacterial microbiota, with the abundance of a considerable number of genera being severely diminished. This shift was particularly evident for the dominant genera found in healthy plants; namely, Hymenobacter (47.9 to 0.9 and 39.5 to $14.1 \%$ in healthy versus diseased female and male plants, respectively), Sphingomonas (21.3 to 0.9 and 32.7 to $9.5 \%$, in healthy and diseased female and male plants, respectively), and Massilia (10.2 to 0.3 and 11.1 to $3.6 \%$, in healthy and diseased female and male plants, respectively), with this reduction being more pronounced in female plants (Fig. 3A). These results were supported by the $\alpha$-diversity indexes, reflecting a decrease in bacterial diversity and evenness between diseased female plants with the emergence of a dominant taxon in the latter, the genus Pseudomonas. The profound impact caused by $P$. syringae pv. actinidiae infection in the bacterial microbiota of female plants during spring was more pronounced than in male plants. This was also supported by the difference between the values obtained for the diversity indexes for healthy and diseased plants (Table 1).

A distinct trend was observed in autumn (Fig. 3B). Contrary to what was observed in spring, the shared bacterial microbiota structure for diseased plants in autumn was identical to the one defined for healthy plants, corroborated by a Jaccard diversity index of 0.91 . P. syringae pv. actinidiae infection induced similar changes in female and male plants in autumn (Fig. 3B). In detail, Methylobacterium was the dominant genera in this season among infected plants (15.9 to $44.3 \%$ in female plants, healthy versus diseased,

TABLE 1

$\alpha$-Diversity for each sample ${ }^{a}$

\begin{tabular}{|c|c|c|c|c|c|}
\hline Sample & OTUs & Coverage & Shannon index $\left(\mathrm{H}^{\prime}\right)$ & Simpson reciprocal index (1/D') & Pielou index $\left(\mathrm{J}^{\prime}\right)$ \\
\hline S_FH & 44 & 0.98 & 1.67 & 0.71 & 0.57 \\
\hline S_MH & 45 & 0.98 & 1.6 & 0.72 & 0.54 \\
\hline A_MH & 50 & 0.99 & 1.86 & 0.77 & 0.59 \\
\hline S_FD & 36 & 0.99 & 0.17 & 0.05 & 0.06 \\
\hline A_FD & 48 & 0.99 & 1.84 & 0.75 & 0.6 \\
\hline A_MD & 46 & 0.99 & 1.79 & 0.79 & 0.59 \\
\hline
\end{tabular}


A
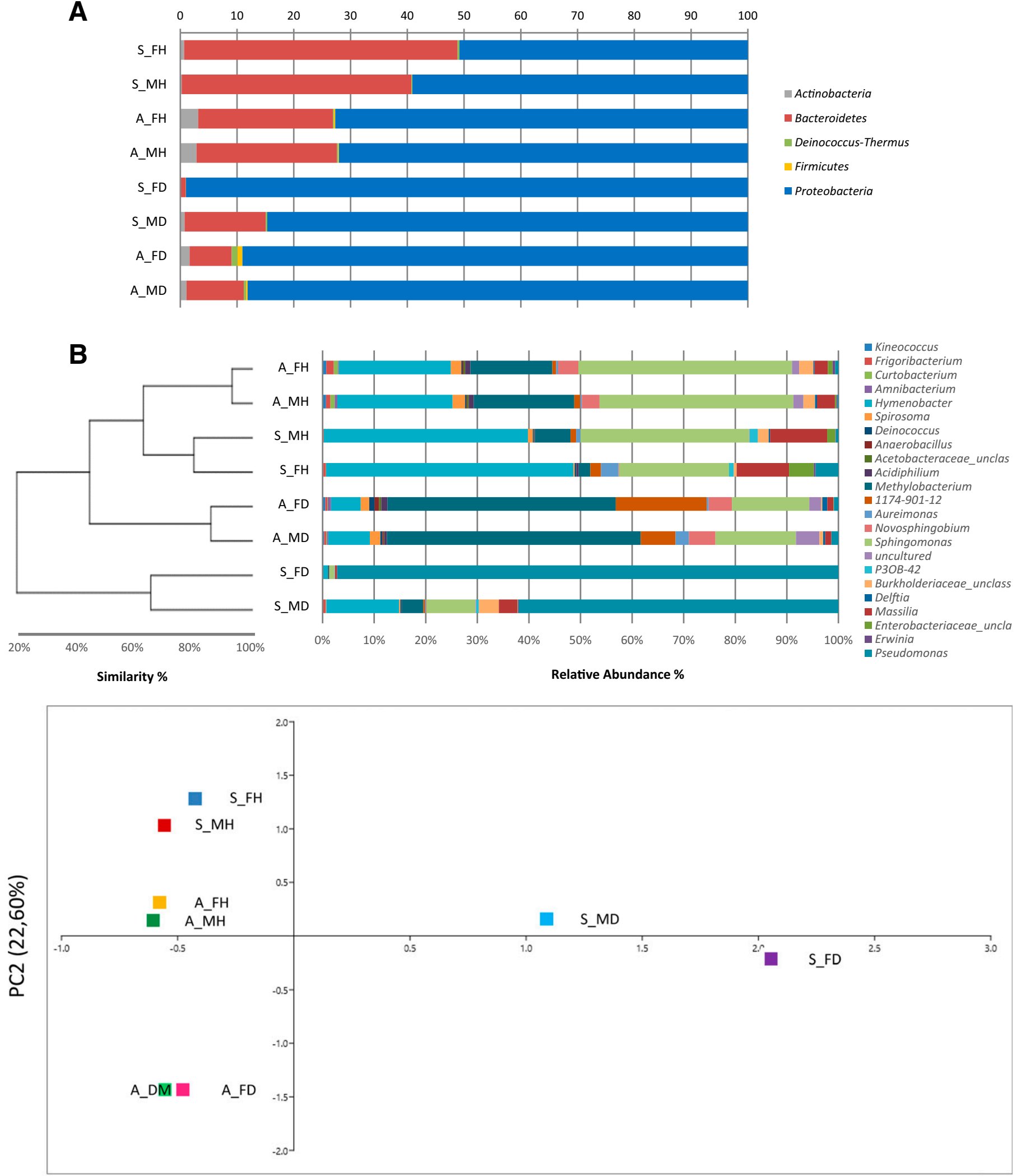

PC1 (72,92\%)

Fig. 1. Bacterial community structure and relative abundance analyzed at the A, phylum level and $\mathbf{B}$, genus level for the different samples. The dendrogram of the bacterial community structure was created using the unweighted pair-group method with arithmetic means. The relative abundance of the predominant bacterial orders is plotted for each sample. Only bacterial classes higher in abundance than $1 \%$ were included. Principal component analysis (PCA) plot shows variation among samples according to the structural diversity. S_FD = diseased females in spring, S_MD = diseased males in spring, S_FH = healthy females in spring, S_MH = healthy males in spring, $A \_F H=$ healthy females in autumn, A_MH $=$ healthy males in autumn, A_MD = diseased males in autumn, and A_FD = diseased females in autumn. 
respectively; and 19.5 to $49.2 \%$ in male plants, healthy versus diseased, respectively), followed by genus Sphingomonas (41.4 to $15.0 \%$ in female plants, healthy versus diseased, respectively; and 37.6 to $15.6 \%$ in male plants, healthy versus diseased, respectively) and genus Hymenobacter (21.7 to $5.8 \%$ in female plants, healthy versus diseased, respectively; and 22.3 to $8.1 \%$ in male plants, healthy versus diseased, respectively). Genus 1174-901-12 experienced a considerable increase in abundance in infected plants $(0.8$ to $17.6 \%$ in female plants, healthy versus diseased, respectively; and 1.2 to $6.8 \%$ in male plants, healthy versus diseased, respectively), whereas genera Burkholderiaceae_unclassified and Massilia exhibited a reduction in their values (Fig. 3B). Also, genus Erwinia was absent from the bacterial microbiota of infected plants, while Enterobacteriaceae_unclassified was not identified in infected male plants (Fig. 3B). The $\alpha$-diversity indexes supported these findings with similar values of diversity, dominance, and evenness for healthy and infected female and male kiwifruit plants (Table 1). These results allowed to determine that the presence of $P$. syringae pv. actinidiae was responsible for a deep change in the plant bacterial microbiota and that this change varied with the seasons (Fig. 1B).

However, did the $P$. syringae pv. actinidiae infection induce similar changes in the bacterial community of female and male plants? Considering the overall average dissimilarity between diseased female and male plants (35.2\% in spring and $14.4 \%$ in autumn), we could argue that both plants were affected in a similar way (Supplementary Table S3), indicating the same connection previously observed between healthy plants in both seasons (Supplementary Fig. S1). Moreover, these results were depicted in the PCA, indicating clear differences between healthy and infected kiwifruit plants, as well as reflecting the cumulative impact of seasons in the composition of the leaf bacterial microbiota (Fig. 1B).

Recent studies described phytohormones as key regulators of plant immunity (Denancé et al. 2013). The production of hormones varies according to the reproductive state of the plant and after a pathogen introduction (Denancé et al. 2013). It was observed by Froud et al. (2015) that kiwifruit male plants exhibit a higher incidence of symptoms than female plants, suggesting that they are more susceptible to disease. It is known that there are male plants in which the development of the vegetative stage begins earlier

TABLE 2

$\beta$-Diversity (top diagonal) and overall average dissimilarity between different samples (bottom diagonal) ${ }^{a}$

\begin{tabular}{lccccccccc}
\hline Sample & S_FH & S_MH & S_FD & S_MD & A_FH & A_MH & A_FD & A_MD \\
\hline S_FH & - & 0.76 & 0.65 & 0.85 & 0.74 & 0.78 & 0.69 & 0.69 \\
\hline S_MH & $\mathbf{2 0 . 3}$ & - & 0.78 & 0.74 & 0.78 & 0.82 & 0.74 & 0.74 \\
\hline S_FD & 92.73 & 90.6 & - & 0.56 & 0.60 & 0.65 & 0.56 & 0.56 \\
\hline S_MD & 63.0 & 64.1 & $\mathbf{3 5 . 2}$ & - & 0.87 & 0.91 & 0.82 & 0.82 \\
\hline A_FH & $\underline{46.9}$ & 29.5 & 96.6 & 64.0 & - & 0.95 & 0.95 & 0.87 \\
\hline A_MH & 46.2 & $\underline{28.6}$ & 97.0 & 64.1 & 7.0 & - & 0.91 & 0.91 \\
\hline A_FD & 70.4 & 066.9 & 96.4 & 76.3 & 49.9 & 46.0 & - & 0.90 \\
\hline A_MD & 64.5 & 63.1 & 95.9 & 73.1 & 47.2 & 43.4 & 14.4 & - \\
\hline
\end{tabular}

S_FD $=$ diseased females in spring, S_MD $=$ diseased males in spring, S_FH = healthy females in spring, S_MH = healthy males in spring, A_FH = healthy females in autumn, $A \_M H=$ healthy males in autumn, A_MD = diseased males in autumn, and A_FD = diseased females in autumn. Underline indicates average dissimilarity between female/female and male/male plants in spring and autumn, and bold indicates average dissimilarity between healthy male/female and diseased male/female in spring. than in female plants and they produce more flowers, which may result in differences in some hormone pathway (during the same timeframe) that could contribute to reducing pathogen susceptibility in female plants whereas, in contrast, it could affect plant growth and resistance in male plants (Denancé et al. 2013). In the absence of a precise quantification of $P$. syringae pv. actinidiae, the differences in Pseudomonas spp. abundance may not be strictly indicative of $P$. syringae pv. actinidiae presence because several other Pseudomonas spp., including beneficial or commensal strains, are often found on plants. This hypothesis is in line with the results obtained by Purahong et al. (2018), who observed that $P$. syringae pv. actinidiae in association with other Pseudomonas spp. produced a more efficient infection by modifying the bacterial communities present. This observation is corroborated by Donati et al. (2020), who describe the signaling systems allowing the coordination of the Pseudomonas-pathogenic consortium in Actinidia spp. Thus, the interaction between $P$. syringae pv. actinidiae and the bacterial communities on the leaves seems to be crucial for the outcome of the infection process.

Methylotrophs such as species from the genus Methylobacterium dominate the leaf surface communities and possess adaptations to cope with the extreme conditions of these ecological niches (Vorholt 2012). Those adaptations provide leverage when competing with other bacterial populations and may lead to the exclusion of some bacterial populations, including plant pathogens (Vandenkoornhuyse et al. 2015). This could explain the low relative abundance value of the genus Pseudomonas and the increase in the relative abundance value for genus Methylobacterium in autumn. Dourado et al. (2015) described that genus Methylobacterium is involved in the colonization of the plant in response to a stressful situation. Different species of Methylobacterium produce plantgrowth-promoting hormones (McGarvey et al. 2014). Ryu et al. (2006) showed that the inoculation with Methylobacterium spp., known to produced indole acetic acid, promoted the growth of tomato (Lycopersicon esculentum L.) and of red pepper (Capsicum annuum L.) plants. Members of genus Sphingomonas produce growth factors and generally protect plants by reducing the number of pathogens present because they compete with them for nutrients (Innerebner et al. 2011). The ability of Sphingomonas spp. to protect A. thaliana against Xanthomonas campestris has been previously described (Innerebner et al. 2011), in parallel with the role of $S$. paucimobilis as an antagonist against the phytopathogenic fungus Verticillium dahliae (White et al. 1996). The genus Pseudomonas is another group that, although including pathogenic bacteria, encompasses some species with the capacity to produce antibiotics, siderophores and a wide variety of low molecular weight metabolites with antifungal or antibacterial activity against some pathogens (De-Bashan et al. 2007). Therefore, the above mentioned bacterial groups comprise good candidates for isolation efforts in future work to determine bacterial cultures with potential capacity as $P$. syringae pv. actinidiae antagonists or with a role in the modulation of the damage extent of the kiwifruit bacterial canker.

Effect of the season on the bacterial community of $A$. chinensis var. deliciosa leaves. The role of the season (spring and autumn) is related to the changes in environmental conditions and provided useful information about the behavior of Pseudomonas spp. (and, most likely, of $P$. syringae pv. actinidiae) in key moments of the disease cycle. Furthermore, it was considered statistically significance by the GLM, as previously discussed. In the absence of chemical control with copper products and the absence of fertilization procedures in the 2 years prior to sampling, we could exclude the effect that any treatment could have in influencing or shaping the bacterial microbiome. Those conditions affected our choice for these particular orchards to be used in this study. It 
TABLE 3

Similarity percentages (SIMPER) analysis using PAST was used to calculate the overall average dissimilarity (Avg) between different samples and obtain the identity and relative abundances of the bacterial taxa that contributed most to the observed pairwise variation in the bacterial community composition due to seasons and Pseudomonas syringae pv. actinidiae infection ${ }^{\mathrm{a}}$

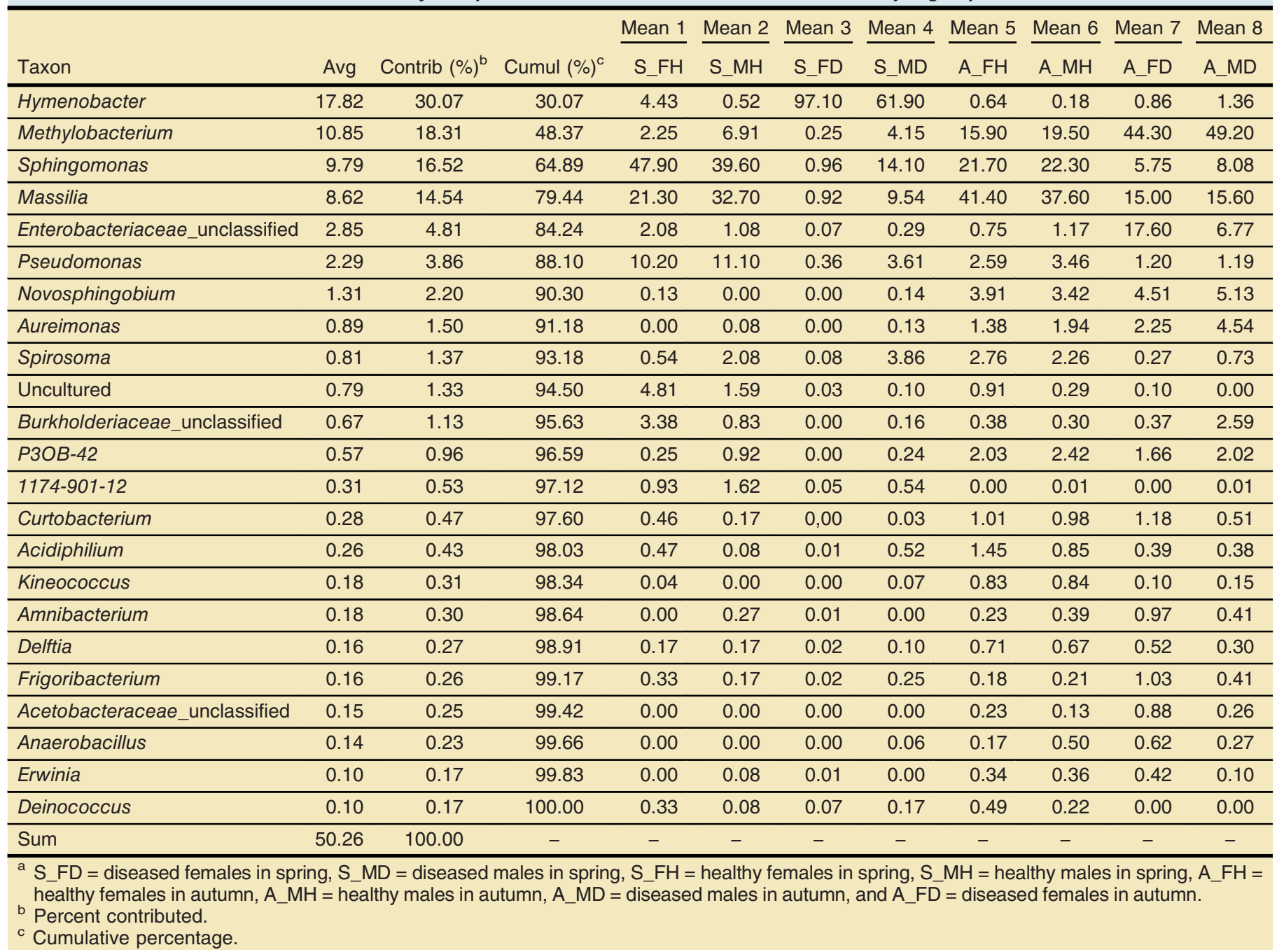

A n =

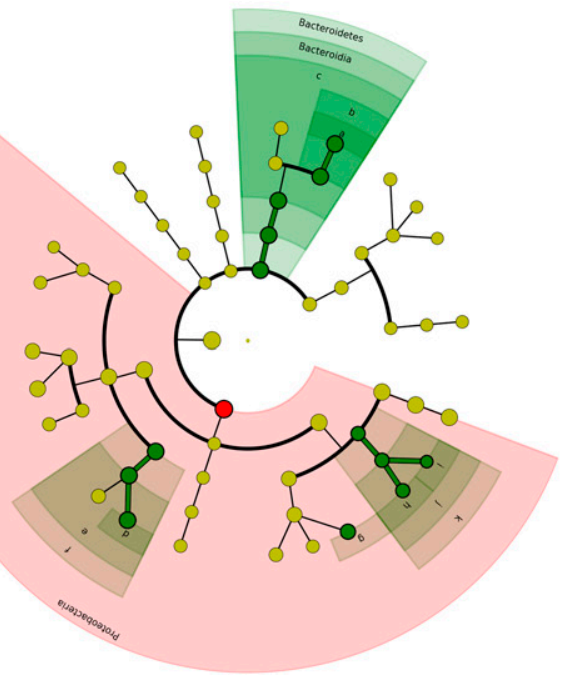

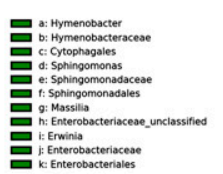

B

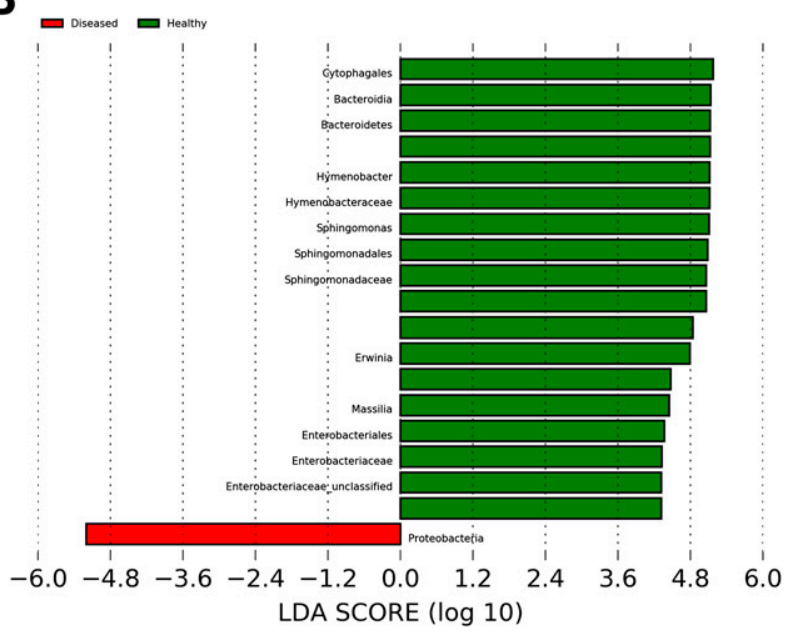

Fig. 2. Linear discriminant analysis (LDA) effect size (LEfSe) was used to identify the most differentially abundant taxa among healthy and diseased plants. A, Cladogram generated by LEfSe indicating differences of bacteria at phylum, class, family, and genus levels (relative abundance $\leq 0.5 \%$ ). Each successive circle represents a phylogenetic level. Red and green circles indicate that healthy (green) and diseased (red) showed differences in relative abundance and yellow circles indicate nonsignificant differences. Differing taxa are listed on the right side of the cladogram. B, Only taxa meeting an LDA significant threshold $>2$ are shown. 
FEMALE SPRING

A

\begin{tabular}{|l|c|c|}
\hline Kineococcus & 0.17 & 0.02 \\
\hline Frigoribacterium & 0.47 & 0.01 \\
\hline Curtobacterium & 0.04 & 0.00 \\
\hline Amnibacterium & 0.00 & 0.00 \\
\hline Hymenobacter & 47.93 & 0.96 \\
\hline Spirosoma & 0.25 & 0.00 \\
\hline Deinococcus & 0.33 & 0.02 \\
\hline Anaerobacillus & 0.00 & 0.00 \\
\hline Acetobacteraceae_unclassified & 0.00 & 0.01 \\
\hline Acidiphilium & 0.46 & 0.00 \\
\hline Methylobacterium & 2.25 & 0.25 \\
\hline 1174-901-12 & 2.08 & 0.07 \\
\hline Aureimonas & 3.38 & 0.00 \\
\hline Novosphingobium & 0.13 & 0.00 \\
\hline Sphingomonas & 21.31 & 0.92 \\
\hline Sphingomonadaceae_uncultured & 0.00 & 0.00 \\
\hline P3OB-42 & 0.93 & 0.05 \\
\hline Burkholderiaceae_unclassified & 0.54 & 0.08 \\
\hline Delftia & 0.00 & 0.01 \\
\hline Massilia & 10.17 & 0.36 \\
\hline Enterobacteriaceae_unclassified & 4.81 & 0.03 \\
\hline Erwinia & 0.33 & 0.07 \\
\hline Pseudomonas & 4.43 & 97.15 \\
\hline
\end{tabular}

FEMALE AUTUMN

B

\begin{tabular}{|l|c|c|}
\multicolumn{1}{c}{} & \multicolumn{1}{c}{ FEMALE AUTUMN } \\
\cline { 2 - 3 } \multicolumn{1}{l|}{} & HEALTHY & DISEASE \\
\hline Kineococcus & 0.71 & 0.52 \\
\hline Frigoribacterium & 1.45 & 0.39 \\
\hline Curtobacterium & 0.83 & 0.10 \\
\hline Amnibacterium & 0.16 & 0.62 \\
\hline Hymenobacter & 21.71 & 5.75 \\
\hline Spirosoma & 2.03 & 1.66 \\
\hline Deinococcus & 0.18 & 1.03 \\
\hline Anaerobacillus & 0.23 & 0.88 \\
\hline Acetobacteraceae_unclassified & 0.34 & 0.42 \\
\hline Acidiphilium & 1.01 & 1.18 \\
\hline Methylobacterium & 15.88 & 44.27 \\
\hline 1174-901-12 & 0.75 & 17.64 \\
\hline Aureimonas & 0.38 & 0.37 \\
\hline Novosphingobium & 3.91 & 4.51 \\
\hline Sphingomonas & 41.43 & 14.99 \\
\hline Sphingomonadaceae_uncultured & 1.38 & 2.25 \\
\hline P3OB-42 & 0.00 & 0.00 \\
\hline Burkholderiaceae_unclassified & 2.76 & 0.27 \\
\hline Delftia & 0.23 & 0.97 \\
\hline Massilia & 2.59 & 1.20 \\
\hline Enterobacteriaceae_unclassified & 0.91 & 0.10 \\
\hline Erwinia & 0.49 & 0.00 \\
\hline Pseudomonas & 0.64 & 0.86 \\
\hline
\end{tabular}

MALE SPRING

\begin{tabular}{|c|c|}
\hline HEALTHY & DISEASE \\
\hline 0.17 & 0.10 \\
\hline 0.08 & 0.52 \\
\hline 0.00 & 0.07 \\
\hline 0.00 & 0.06 \\
\hline 39.58 & 14.09 \\
\hline 0.92 & 0.24 \\
\hline 0.17 & 0.25 \\
\hline 0.00 & 0.00 \\
\hline 0.08 & 0.00 \\
\hline 0.17 & 0.03 \\
\hline 6.91 & 4.15 \\
\hline 1.08 & 0.29 \\
\hline 0.83 & 0.16 \\
\hline 0.00 & 0.14 \\
\hline 32.71 & 9.54 \\
\hline 0.08 & 0.13 \\
\hline 1.62 & 0.54 \\
\hline 2.08 & 3.86 \\
\hline 0.27 & 0.00 \\
\hline 11.07 & 3.61 \\
\hline 1.59 & 0.10 \\
\hline 0.08 & 0.17 \\
\hline 0.52 & 61.95 \\
\hline & \\
\hline
\end{tabular}

MALE AUTUMN

\begin{tabular}{|c|c|}
\hline HEALTHY & DISEASE \\
\hline 0.67 & 0.30 \\
\hline 0.85 & 0.38 \\
\hline 0.84 & 0.15 \\
\hline 0.50 & 0.27 \\
\hline 22.34 & 8.08 \\
\hline 2.42 & 2.02 \\
\hline 0.21 & 0.41 \\
\hline 0.13 & 0.26 \\
\hline 0.36 & 0.10 \\
\hline 0.98 & 0.50 \\
\hline 19.48 & 49.18 \\
\hline 1.17 & 6.77 \\
\hline 0.30 & 2.59 \\
\hline 3.42 & 5.13 \\
\hline 37.58 & 15.62 \\
\hline 1.94 & 4.54 \\
\hline 0.01 & 0.01 \\
\hline 2.26 & 0.73 \\
\hline 0.39 & 0.41 \\
\hline 3.46 & 1.19 \\
\hline 0.29 & 0.00 \\
\hline 0.22 & 0.00 \\
\hline 0.18 & 1.37 \\
\hline & \\
\hline
\end{tabular}

Fig. 3. Heatmap of the relative abundance (percentage) of genera between healthy and infected female and male plants in $\mathbf{A}$, spring and $\mathbf{B}$, autumn. The color scale indicates the abundance ranking of the relative genera: highest (red), midpoint with $50 \%$ percentile (yellow), and lowest (white). 
should be noted that, in our study, the healthy and diseased orchards were 30 and 9 years old, respectively, and that plant age has been reported as a factor that affects the bacterial communities associated with a host. Independent of the age factor, the results obtained showed that kiwifruit plants harbored a distinct bacterial microbiota according to the season. This result was confirmed by the Kruskal-Wallis test with a $P$ value $<0.05(P=0.000)$, which indicated that there were statistically significant differences between spring and autumn seasons. Statistics for the $P$ value of the pairwise comparisons of the samples for each season are shown in Supplementary Table S2.

The LEfSe analysis identified 31 differentially abundant taxa among seasons (five in spring and 26 in autumn) on kiwifruit leaves (Fig. 4). Gammaproteobacteria and Deltaproteobacteria, Mixococcales, and $P 3 O B-42$ and $P 3 O B-42$ were the major classes, family, and genera, respectively, that contributed to differentiate the bacterial communities in spring. In autumn, the differences were due to the contribution of two phyla (i.e., Firmicutes and Actinobacteria); some classes, namely, Bacilli, Actinobacteria, and Alphaproteobacteria; at the order level, Kineosporiales, Acetobacterales, Microccocales, Bacilliales, and Rhizobiales; at the family level, Bacilliaecae, Kineosporiaceae, Spirosomaceae, Acetobacteraceae, Microbacteriaceae, Beijerinckiaceae, and Acetobacterceae_unclassified; and at the genus level, Delftia, Anaerobacillus, Amnibacterium, Kineococcus, Siprisoma, Curtobacterium, Acidiphilum, Methylobacterium, and Novosphingobium.

The differences were mainly due to changes in the relative abundance of the most abundant taxa. This was visible in the dissimilarity values determined between healthy samples (Tables 2 and 3), as in the cluster-based analysis of bacterial community structure and composition, where healthy kiwifruit plants clustered by season
(Fig. 1B). The overall average dissimilarity between female/female and male/male plants, in spring and autumn, was 46.9 and $28.6 \%$, respectively (Tables 2 and 3, results underlined). Moreover, the shift in the relative abundance of some taxa was supported by the Jaccard diversity index, with values of 0.74 between female plants and 0.82 between male plants.

In a general perspective, the major differences observed in the bacterial community of healthy plants between spring and autumn were related to the increase in the relative percentage of phyla Proteobacteria, Deinococcus-Thermus, and Firmicutes, with a concomitant decrease in phylum Bacterioidetes (Fig. 1A). At the genus level, the dominant genera shift between seasons (Fig. 1B). Whereas, in spring, a clear dominance of Hymenobacter was registered, followed by Sphingomonas and Massilia, in autumn, the relative abundance of Hymenobacter was nearly half of the value determined in spring, while Sphingomonas became the dominant genus, followed by Hymenobacter and Methylobacterium (Fig. 5A). The methodology used in this study does not distinguish between endophytic and epiphytic bacterial communities but these oscillations in the relative abundance in dominant genera were reported as particularly characteristic of bacterial endophytes that are susceptible to environmental changes associated with seasonal changes (Ding and Melcher 2016). Moreover, genus Pseudomonas was detected in residual values in autumn when compared with the relative abundance determined in spring. In contrast, genus Novosphingobium experienced a considerable increase in autumn (Fig. 5A).

In detail, a higher bacterial diversity was observed in autumn when compared with spring which, combined with the existence of dominant genera, translates to low equitability. These results were corroborated by the diversity indices obtained (Table 1).
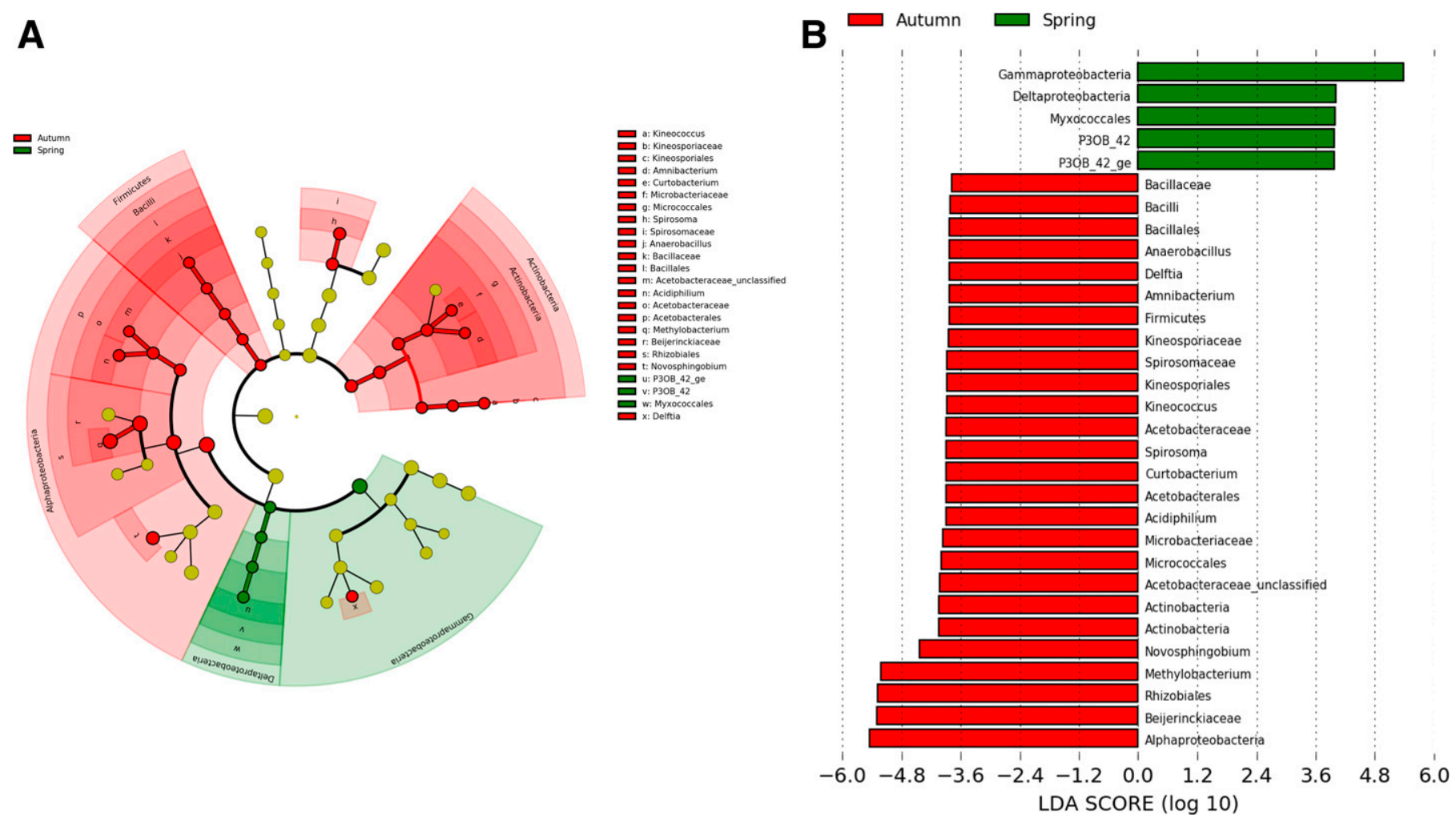

Fig. 4. Linear discriminant analysis (LDA) effect size (LEfSe) was used to identify the most differentially abundant taxa among autumn and spring plants. A, Cladogram generated by LEfSe indicating differences of bacteria at phylum, class, family, and genus levels (relative abundance $\leq 0.5 \%$ ). Each successive circle represents a phylogenetic level. Red and green circles indicate that spring (green) and autumn (red) showed differences in relative abundance and yellow circles indicate nonsignificant differences. Differing taxa are listed on the right side of the cladogram. B, Only taxa meeting an LDA significant threshold $>2$ are shown. 


\begin{tabular}{l|l|c|}
\multicolumn{2}{l}{} \\
\cline { 2 - 3 } & \multicolumn{2}{c}{ SPRING } \\
\cline { 2 - 3 } & FEMALE & MALE \\
\hline Kineococcus & 0.17 & 0.17 \\
\hline Frigoribacterium & 0.47 & 0.08 \\
\hline Curtobacterium & 0.04 & 0.00 \\
\hline Amnibacterium & 0.00 & 0.00 \\
\hline Hymenobacter & 47.93 & 39.58 \\
\hline Spirosoma & 0.25 & 0.92 \\
\hline Deinococcus & 0.33 & 0.17 \\
\hline Anaerobacillus & 0.00 & 0.00 \\
\hline Acetobacteraceae_unclassified & 0.00 & 0.08 \\
\hline Acidiphilium & 0.46 & 0.17 \\
\hline Methylobacterium & 2.25 & 6.91 \\
\hline 1174-901-12 & 2.08 & 1.08 \\
\hline Aureimonas & 3.38 & 0.83 \\
\hline Novosphingobium & 0.13 & 0.00 \\
\hline Sphingomonas & 21.31 & 32.71 \\
\hline Sphingomonadaceae_uncultured & 0.00 & 0.08 \\
\hline P3OB-42 & 0.93 & 1.62 \\
\hline Burkholderiaceae_unclassified & 0.54 & 2.08 \\
\hline Delftia & 0.00 & 0.27 \\
\hline Massilia & 10.17 & 11.07 \\
\hline Enterobacteriaceae_unclassified & 4.81 & 1.59 \\
\hline Erwinia & 0.33 & 0.08 \\
\hline Pseudomonas & 4.43 & 0.52 \\
\hline
\end{tabular}

AUTUMN

\begin{tabular}{|c|c|}
\hline FEMALE & MALE \\
\hline 0.71 & 0.67 \\
\hline 1.45 & 0.85 \\
\hline 0.83 & 0.84 \\
\hline 0.16 & 0.50 \\
\hline 21.71 & 22.34 \\
\hline 2.03 & 2.42 \\
\hline 0.18 & 0.21 \\
\hline 0.23 & 0.13 \\
\hline 0.34 & 0.36 \\
\hline 1.01 & 0.98 \\
\hline 15.88 & 19.48 \\
\hline 0.75 & 1.17 \\
\hline 0.38 & 0.30 \\
\hline 3.91 & 3.42 \\
\hline 41.43 & 37.58 \\
\hline 1.38 & 1.94 \\
\hline 0.00 & 0.01 \\
\hline 2.76 & 2.26 \\
\hline 0.23 & 0.39 \\
\hline 2.59 & 3.46 \\
\hline 0.91 & 0.29 \\
\hline 0.49 & 0.22 \\
\hline 0.64 & 0.18 \\
\hline
\end{tabular}

\begin{tabular}{l|c|c|}
\multicolumn{2}{|c}{ B } & \multicolumn{2}{c}{ FEMALE } \\
\cline { 2 - 4 } & SRING & AUTUMN \\
\hline Kineococcus & 0.17 & 0.71 \\
\hline Frigoribacterium & 0.47 & 1.45 \\
\hline Curtobacterium & 0.04 & 0.83 \\
\hline Amnibacterium & 0.00 & 0.16 \\
\hline Hymenobacter & 47.93 & 21.71 \\
\hline Spirosoma & 0.25 & 2.03 \\
\hline Deinococcus & 0.33 & 0.18 \\
\hline Anaerobacillus & 0.00 & 0.23 \\
\hline Acetobacteraceae_unclassified & 0.00 & 0.34 \\
\hline Acidiphilium & 0.46 & 1.01 \\
\hline Methylobacterium & 2.25 & 15.88 \\
\hline 1174-901-12 & 2.08 & 0.75 \\
\hline Aureimonas & 3.38 & 0.38 \\
\hline Novosphingobium & 0.13 & 3.91 \\
\hline Sphingomonas & 21.31 & 41.43 \\
\hline Sphingomonadaceae_uncultured & 0.00 & 1.38 \\
\hline P3OB-42 & 0.93 & 0.00 \\
\hline Burkholderiaceae_unclassified & 0.54 & 2.76 \\
\hline Delftia & 0.00 & 0.23 \\
\hline Massilia & 10.17 & 2.59 \\
\hline Enterobacteriaceae_unclassified & 4.81 & 0.91 \\
\hline Erwinia & 0.33 & 0.49 \\
\hline Pseudomonas & 4.43 & 0.64 \\
\hline
\end{tabular}

\begin{tabular}{|c|c|}
\hline MRING & AUTUMN \\
\hline 0.17 & 0.67 \\
\hline 0.08 & 0.85 \\
\hline 0.00 & 0.84 \\
\hline 0.00 & 0.50 \\
\hline 39.58 & 22.34 \\
\hline 0.92 & 2.42 \\
\hline 0.17 & 0.21 \\
\hline 0.00 & 0.13 \\
\hline 0.08 & 0.36 \\
\hline 0.17 & 0.98 \\
\hline 6.91 & 19.48 \\
\hline 1.08 & 1.17 \\
\hline 0.83 & 0.30 \\
\hline 0.00 & 3.42 \\
\hline 32.71 & 37.58 \\
\hline 0.08 & 1.94 \\
\hline 1.62 & 0.01 \\
\hline 2.08 & 2.26 \\
\hline 0.27 & 0.39 \\
\hline 11.07 & 3.46 \\
\hline 1.59 & 0.29 \\
\hline 0.08 & 0.22 \\
\hline 0.52 & 0.18 \\
\hline
\end{tabular}

Fig. 5. Heatmap of the relative abundance (percentage) of genera between female and male healthy kiwi plants $\mathbf{A}$, in the same season and $\mathbf{B}$, between seasons. The color scale indicates the abundance ranking of the relative genera: highest (red), midpoint with $50 \%$ percentile (yellow), and lowest (white). 
A thorough analysis of the leaf bacterial microbiota from healthy plants allowed us to identify specific genera for each season. Genera Amnibacterium, Anaerobacillus, Acetobacteraceae, one genus of uncultured bacteria belonging to family Sphingomonadaceae, and genus Delftia were only detected in autumn, while other genera such as P3OB-42, Amnibacterium, Anaerobacillus, and Novosphingobium were restricted to the leaf bacterial microbiota of healthy plants in spring (Fig. 5).

Although our study describes the bacterial communities present in leaves, $P$. syringae pv. actinidiae can penetrate inside the plants: through natural openings in leaves such as lenticels, fruit stalks, leaf scars, and pruning wounds caused by agriculture practices (Donati et al. 2020). Infection in spring normally occurs in leaves and during autumn within the vascular system (Ferrante et al. 2012). Spring and autumn seasons are two key control points in the cycle of $P$. syringae pv. actinidiae but it should be remembered that the results obtained for spring sampling were interpreted as reflecting the bacterial communities' response to spring and early summer environmental conditions and the results obtained for autumn sampling as reflecting the bacterial communities' response to summer to earlyautumn environmental conditions, not to the autumn season.

Our results are difficult to compare with those of Purahong et al. (2018), which were obtained with samples only in the springtime and versed to describe the bacterial microbiome of healthy and disease plants. Our work also contemplated seasonal changes in the bacterial microbiome, because its impact has never been studied in kiwi fruit plants, despite seasonality being reported as one of the main factors responsible for changes in the microbial communities' structural diversity within most plants (Babalola et al. 2020). Furthermore, several authors described differences in the microbiome composition between seasons in other crops or even in perennial grasses (Grady et al. 2019; Ou et al. 2019).

Gender effect on the bacterial communities of $A$. chinensis var. deliciosa leaves. The gender factor was irrelevant in the clustering of samples because, as mentioned above, plant samples were grouped by season. These results were confirmed by the GLM ( $F=$ $0.30 ; P=0.58)$ and later corroborated by Kruskal-Wallis $(P=$ 0.971), which showed that the differences between female and male kiwifruit plants were not statistically significant at a $95.0 \%$ confidence level. Statistics for $P$ value of the pairwise comparisons of the samples for each gender are presented in Supplementary Table S2.

Our work studied the bacterial communities on leaves, because it has been described that differences exist in the susceptibility to $P$. syringae pv. actinidiae between female and male plants (Donati et al. 2020), and this was the motive to introduce the factor of gender in our model. It is true that, in an A. chinensis var. deliciosa orchard, the number of female plants is always higher than that of male plants; however, the latter are of great importance for natural pollination. Recently, it was described by Donati and colleagues (2020) that the $P$. syringae pv. actinidiae infection threshold on leaves of male A. chinensis var. deliciosa 'Tomuri' plants was lower than that of female Hayward; thus, in this study, we wanted to investigate whether that difference would be translated into differences in the structural diversity of bacterial communities of leaves of healthy plants in both genders.

The comparison between the results of metabarcoding data of healthy female and male kiwifruit plants provided evidence of the existence of a bacterial microbiota shared by healthy female and male kiwifruit plants (Table 2, results in bold) despite the differences on their relative abundance (Fig. 1B).

In spring, in both genders, genus Hymenobacter was dominant (47.9\% in female and $39.6 \%$ in male plants), followed by genera Sphingomonas, Massilia, Methylobacterium, one unclassified genus belonging to family Enterobacteriaceae, and genus Pseudomonas (Fig. 2A). Differences were observed in their relative abundance between genders; namely, Sphingomonas and Methylobacterium were recovered in higher relative abundance in male plants than in female plants, at 32.7 versus $21.3 \%$ and 6.9 versus $2.2 \%$, respectively (Fig. 5A). In contrast, genera Hymenobacter, Pseudomonas, Aureimonas, and two unclassified genera belonging to families Enterobacteriaceae and Beijerinckiaceae were recovered in higher relative abundance in female plants (Fig. 3A). Several species of genus Pseudomonas have been reported in kiwifruit, some as pathogens while others are nonpathogens and, for this reason, it is worth noticing the differences observed between genders on the relative abundance of this genus ( $4.4 \%$ in female plants versus $0.5 \%$ in male plants) (Supplementary Table S1; Fig. 5A). The existence of a shared bacterial microbiota among both healthy kiwifruit plant genders was supported by dissimilarity indexes; the lowest values of this index are translated into a greater similarity (Table 1).

In autumn, in both genders, the bacterial microbiota of $A$. chinensis var. deliciosa leaves were also identical in structure but with substantial differences in taxa relative abundance. In detail, Sphingomonas was the dominant genus in autumn $(41.4 \%$ in female and $37.6 \%$ in male plants), followed by Hymenobacter $(21.7 \%$ in female and $22.3 \%$ in male plants) and Methylobacterium (15.9\% in female and $19.5 \%$ in male). The relative abundance of genera Massilia, an unclassified genus of Enterobacteriaceae, and Pseudomonas decreased when compared with spring microbiota, whereas an unclassified genus of Burkholderiaceae (2.7\% in female and $2.2 \%$ in male) and Novosphingobium increased in autumn (3.9\% in female and $3.4 \%$ in male) (Supplementary Table S1; Fig. 5A). The overall results were supported by the diversity indexes that confirmed the existence of dominant genera and a similar degree of diversity between genders for female and male kiwifruit plants (Table 1). Taxa differences between female and male kiwifruit plants were not statistically significant according to LEfSe analysis. However, it has been reported that a given plant cultivar can shape the bacterial communities (Bodenhausen et al. 2014), helping to explain to some extent the differences observed in this study between the bacterial microbiota of male A. chinensis var. deliciosa 'Tomuri' and female Hayward plants.

Conclusions. This study characterizes the bacterial communities from leaves of $A$. chinensis var. deliciosa (the most important commercial species in Portugal), cultivated in organic kiwifruit orchards with no application of copper-based products. The impact of $P$. syringae pv. actinidiae on the bacterial community structure of male and female plants in two distinct seasons was also addressed.

Our results demonstrate that the leaf bacterial microbiota is season specific in healthy female and male kiwifruit plants, with a substantial increase of the relative abundance of genus Methylobacterium in autumn; nevertheless, most taxa were present in both seasons. $P$. syringae pv. actinidiae infection affected the diversity and structure of the bacterial microbiota in male and female plants, translated into a reduction in the relative abundance of previously dominant genera that had been found in healthy plants; namely, Hymenobacter, Sphingomonas, and Massilia. This impact of $P$. syringae pv. actinidiae was less pronounced in both seasons. Finally, the results obtained in this work will allow the development of strategies for the control of bacterial canker of kiwifruit in the two more important points to the infection process (spring and autumn) because some of the identified genera have the potential to act as antagonist or biocontrol agents of plant pathogens.

\section{ACKNOWLEDGMENTS}

We thank the kiwifruit orchard owner of "Delicias do Tojal" for providing the Actinidia samples. 


\section{LITERATURE CITED}

Afzal, I., Shinwari, Z. K., Sikandar, S., and Shahzad, S. 2019. Plant beneficial endophytic bacteria: Mechanisms, diversity, host range and genetic determinants. Microbiol. Res. 221:36-49.

Araújo, W. L., Marcon, J., Maccheroni, W., Van Elsas, J. D., Jim, W. L., and Azevedo, J. L. 2002. Diversity of endophytic bacterial population and their interaction with Xylella fastidiosa in citrus plants. Appl. Environ. Microbiol. 68:4906-4914.

Arrigoni, E., Antonielli, L., Pindo, M., Pertot, I., and Perazzolli, M. 2018. Tissue age and plant genotype affect the microbiota of apple and pear bark. Microbiol. Res. 211:57-68.

Aydogan, E., Moser, G., Müller, C., Kämpfer, P., and Glaeser, S. 2018. Long-term warming shifts the composition of bacterial communities in the phyllosphere of Galium album in a permanent grassland field-experiment. Front. Microbiol. 9:144

Babalola, O. O., Fadiji, A. E., Enagbonma, B. J., Alori, E. T., Ayilara, M. S., and Ayangbenro, A. S. 2020. The nexus between plant and plant microbiome: Revelation of the networking strategies. Front. Microbiol. 11:548037.

Balestra, G. M., Gallipoli, L., Tagliavento, V., Anselmi, A., Ercolani, A., Renzi, M., Mariotti, E., Ciarroni, S., and Mazzaglia, A. 2014. Cancro batterico del kiwi: Strategie di convivenza. Inf. Agrar. 22:50-53.

Balestra, G. M., Mazzaglia, A., and Rossetti, A. 2008. Outbreak of bacterial blossom blight caused by Pseudomonas viridiflava on Actinidia chinensis kiwifruit plants in Italy. Plant Dis. 92:1707.

Berg, G., Köberl, M., Rybakova, D., Müller, H., Grosch, R., and Smalla, K. 2017. Plant microbial diversity is suggested as the key to future biocontrol and health trends. FEMS Microbiol. Ecol. 93:fix050.

Berg, G., Rybakova, D., Grube, M., and Koberl, M. 2016. The plant microbiome explored: Implications for experimental botany. J. Exp. Bot. 67:995-1002.

Berg, M., and Koskella, B. 2018. Nutrient- and dose-dependent microbiomemediated protection against a plant pathogen. Curr. Biol. 28:2487-2492.

Bodenhausen, N., Bortfeld-Miller, M., Ackermann, M., and Vorholt, J. A. 2014. A synthetic community approach reveals plant genotypes affecting the phyllosphere microbiota. PLoS Genetics 10:e1004283.

Buonaurio, R., Moretti, C., da Silva, D. P., Cortese, C., Ramos, C., and Venturi, V. 2015. The olive knot disease as a model to study the role of interspecies bacterial communities in plant disease. Front. Plant Sci. $6: 434$

Buriani, G., Orrù, L., Lamontanara, A., Michelotti, V., Donati, I., Cellini, A. Tacconi, G., and Spinelli, F. 2018. Modification of the phyllosphere bacterial biocoenosis by Pseudomonas syringae pv. actinidiae infection. Acta Hortic. 1218:275-278

Busby, E., Soman, C., Wagner, R., Friesen, L., Kremer, J., Bennett, A., and Dang1, L. 2017. Research priorities for harnessing plant microbiomes in sustainable agriculture. PLoS Biol. 15:e2001793.

Cameron, A., and Sarojini, V. 2014. Pseudomonas syringae pv. actinidiae: Chemical control, resistance mechanisms and possible alternatives. Plant Pathol. 63:1-11.

Chelius, M. K., and Triplett, E. W. 2001. The diversity of archaea and bacteria in association with the roots of Zea mays L. Microb. Ecol. 41:252-263.

De-Bashan, L. E., Holguin, G., Glick, B. R., and Bashan, Y. 2007. Bacterias promotoras de crecimiento en plantas para propositos agricolas y ambientales. Pages 170-224 in: Microbiologia Agrícola: Hongos, Bacterias, Micro y Macrofauna, Control Biologico, Planta-

Microorganismo. R. Ferrera-Cerrato and A. Alarcon, eds. Editorial Trillas, Mexico City, Mexico.

Denancé, N., Sánchez-Vallet, A., Goffner, D., and Molina, A. 2013. Disease resistance or growth: The role of plant hormones in balancing immune responses and fitness costs. Front. Plant Sci. 4:155.

Ding, T., and Melcher, U. 2016. Influences of plant species, season and location on leaf endophytic bacterial communities of non-cultivated plants. PLoS One 11:e0150895.

Do, K. S., Chung, B. N., and Joa, J. H. 2016. D-Psa-K: A model for estimating the accumulated potential damage on kiwifruit canes caused by bacterial canker during the growing and overwintering seasons. Plant Pathol. J. 32:537-544.

Donati, I., Buriani, G., Cellini, A., Mauri, S., Costa, G., and Spinelli, F. 2014. New insights on the bacterial canker of kiwifruit (Pseudomonas syringae pv. actinidiae). J. Berry Res. 4:53-67.
Donati, I., Cellini, A., Sangiorgio, D., Vanneste, J. L., Scortichini, M., Balestra, G. M., and Spinelli, F. 2020. Pseudomonas syringae pv. actinidiae: Ecology, infection dynamics and disease epidemiology. Microb. Ecol. 80:81-102.

Dourado, M. N., Neves, A. A. C., Santos, D. S., and Araújo, W. L. 2015. Biotechnological and agronomic potential of endophytic pink-pigmented methylotrophic Methylobacterium spp. BioMed Res. Int. 2015:909016.

Engelhard, M., Hurek, T., and Reinhold-Hurek, B. 2000. Preferential occurrence of diazotrophic endophytes, Azoarcus spp., in wild rice species and land races of Oryza sativa in comparison with modern races. Environ. Microbiol. 2:131-141

EPPO. 2012. Final pest risk analysis for Pseudomonas syringae pv. actinidiae. EPPO, Paris, France.

EPPO. 2014. PM 7/120 (1) Pseudomonas syringae pv. actinidiae. Bull. OEPP/EPPO Bull. 44:360-375

Ferguson, A. R., Seal, A. G., McNeilage, M. A., Fraser, L. G., Harvey, C. F., and Beatson, R. A. 1996. Kiwifruit. Page 371-418 in: Fruit Breeding. Vol. II: Vine and Small Fruit Crops. J. Janick and J. N. Moore, eds. John Wiley \& Sons, Inc., Oxford, U.K.

Ferrante, P., Fiorillo, E., Marcelletti, S., Marocchi, F., Mastroleo, M., Simeoni, S., and Scortichini, M. 2012. The importance of the main colonization and penetration sites of Pseudomonas syringae pv. actinidiae and prevailing weather conditions in the development of epidemics in yellow kiwifruit, recently observed in Central Italy. J. Plant Pathol. 94:455-461.

Froud, K., Everett, K., Tyson, J., Beresford, R., and Cogger, N. 2015. Review of the risk factors associated with kiwifruit bacterial canker caused by Pseudomonas syringae pv. actinidiae. N. Z. Plant Prot. 68:313327.

Gallelli, A., L'Aurora, A., and Loreti, S. 2011. Gene sequence analysis for the molecular detection of Pseudomonas syringae pv. actinidiae developing diagnostic protocols. J. Plant Pathol. 93:425-435.

Giampetruzzi, A., Baptista, P., Morelli, M., Cameirão, C., Neto, T. L., Costa, D., D’Attoma, G., Kubaa, R. A., Altamura, G., Saponari, M., Pereira, J. A., and Saldarelli, P. 2020. Differences in the endophytic microbiome of olive cultivars infected by Xylella fastidiosa across seasons. Pathogens 9:723

González, A. J., Rodicio, M. R., and Mendoza, M. C. 2003. Identification of an emergent and atypical Pseudomonas viridiflava lineage causing bacteriosis in plants of agronomic importance in a Spanish region. Appl. Environ. Microbiol. 69:2936-2941.

Grady, K. L., Sorensen, J. W., Stopnisek, N., Guittar, J., and Shade, A. 2019. Assembly and seasonality of core phyllosphere microbiota on perennial biofuel crops. Nat. Commun. 10:4135.

Guroo, I., Wani, S. A., Wani, S. M., Ahmad, M., Mir, S. A., and Masoodi, F. A. 2017. A review of production and processing of kiwifruit. J. Food Process. Technol. 8:699.

Hammer, Ø., Harper, D. A. T., and Ryan, P. D. 2001. PAST: Paleontological statistics software package for education and data analysis. Palaeontol. Electron. 4:1-9.

Hanshew, A. S., Mason, C. J., Raffa, K. F., and Currie, C. R. 2013. Minimization of chloroplast contamination in 16S rRNA gene pyrosequencing of insect herbivore bacterial communities. J. Microbiol. Methods 95:149-155.

Innerebner, G., Knief, C., and Vorholt, J. A. 2011. Protection of Arabidopsis thaliana against leaf-pathogenic Pseudomonas syringae by Sphingomonas strains in a controlled model system. Appl. Environ. Microbiol. 77:32023210 .

Jaccard, P. 1912. The distribution of the flora in the alpine zone. New Phytol. 11:37-50.

Kembel, S. W., O'Connor, T. K., Arnold, H. K., Hubbell, S. P., Wright, S. J., and Green, J. L. 2014. Relationships between phyllosphere bacterial communities and plant functional traits in a neotropical forest. Proc. Natl. Acad. Sci. U.S.A. 111:13715-13720.

Kim, M. J., Jeon, C. W., Cho, G., Kim, D. R., Kwack, Y. B., and Kwak, Y. S. 2018. Comparison of microbial community structure in kiwifruit pollens. Plant Pathol. J. 34:143-149.

Köhl, J., Kolnaar, R., and Ravensberg, W. J. 2019. Mode of action of microbial biological control agents against plant diseases: Relevance beyond efficacy. Front. Plant Sci. 10:845.

Lamichhane, J. R., and Venturi, V. 2015. Synergisms between microbial pathogens in plant disease complexes: A growing trend. Front. Plant Sci. 6:385. 
Liu, H., Carvalhais, L. C., Crawford, M., Singh, E., Dennis, P. G., Pieterse, C. M. J., and Scenk, P. M. 2017. Inner plant values: Diversity, colonization and benefits from endophytic bacteria. Front. Microbiol. $8: 2552$.

Liu, J., Abdelfattah, A., Norelli, J., Burchard, E., Schena, L., Droby, S., and Wisniewski, M. 2018. Apple endophytic microbiota of different rootstock/ scion combinations suggests a genotype-specific influence. Microbiome $6: 18$.

McGarvey, J. A., Connell, J. H., Stanker, L. H., and Hnasko, R. 2014. Bacterial population structure and dynamics during the development of almond drupes. J. Appl. Microbiol. 116:1543-1552.

Mari, M., Spadoni, A., and Ceredi, G. 2015. Alternative technologies to control postharvest diseases of kiwifruit. Stewart Postharvest Rev. 4:1-5.

Mauri, S., Cellini, A., Buriani, G., Donati, I., Costa, G., and Spinelli, F. 2016. Optimization of cultural practices to reduce the development of Pseudomonas syringae pv. actinidiae, causal agent of the bacterial canker of kiwifruit. J. Berry Res. 6:355-371.

Monchiero, M., Gullino, M. L., Pugliese, M., Spadaro, D., and Garibaldi, A. 2014. Efficacy of different chemical and biological products in the control of Pseudomonas syringae pv. actinidiae on kiwifruit. Australas. Plant Pathol. 44:13-23.

Ou, T., Xu, W. F., Wang, F., Strobel, G., Zhou, Z. Y., Xiang, Z. H., Liu, J., and Xie, J. 2019. A microbiome study reveals seasonal variation in endophytic bacteria among different mulberry cultivars. Comput. Struct. Biotechnol. J. 17:1091-1100.

Pal, K. K., and Gardener, B. M. 2006. Biological control of plant pathogens. Plant Health Instruct. https://www.apsnet.org/edcenter/disimpactmngmnt/ topc/Pages/BiologicalControl.aspx

Perpetuini, G., Donati, I., Cellini, A., Orrù, L., Giongo, L., Farneti, B., and Spinelli, F. 2019. Genetic and functional characterization of the bacterial community on fruit of three raspberry (Rubus idaeus) cultivars. J. Berry Res. 9:227-247.

Pieterse, C. M. J., Van der Does, D., Zamioudis, C., Leon-Reyes, A., and Van Wees, S. C. M. 2012. Hormonal modulation of plant immunity. Annu. Rev. Cell. Dev. Biol. 28:489-521.

Pinto, C., Pinho, D., Sousa, S., Pinheiro, M., Egas, C., Gomes, A. C. 2014. Unravelling the diversity of grapevine microbiome. PLoS One 9:e85622.

Purahong, W., Orrù, L., Donati, I., Perpetuini, G., Cellini, A., Lamontanara, A., Michelotti, V., Tacconi, G., and Spinelli, F. 2018. Plant microbiome and its link to plant health: Host species, organs and Pseudomonas syringae pv. actinidiae infection shaping bacterial phyllosphere communities of kiwifruit plants. Front. Plant Sci. 9:1563.

Rainey, F. A., Ward-Rainey, N., Kroppenstedt, R. M. , and Stackebrandt, E. 1996. The genus Nocardiopsis represents a phylogenetically coherent taxon and a distinct actinomycete lineage: Proposal of Nocardiomaceae fam. nov. Int. J. Syst. Evol. Microbiol. 46:1088-1092.

Ryu, J.-H., Madhaiyan, M., Poonguzhali, S., Yim, W.-J., Indiragandhi, P., Kim, K.-A., Anandham, R., Yun, J.-C., Kim, K.-H., and Sa, T. 2006. Plant growth substances produced by Methylobacterium spp. and their effect on tomato (Lycopersicon esculentum L.) and red pepper (Capsicum annuum L.) growth. J. Microbiol. Biotechnol. 16:1622-1628.

Schloss, P., Westcott, S., Ryabin, T., Hall, J., Hartmann, M., Hollister, E., and Weber, C. 2009. Introducing mothur: Open-source, platform-independent, community-supported software for describing and comparing microbial communities. Appl. Environ. Microbiol. 75:7537-7541.
Sessitsch, A., and Mitter, B. 2015. 21st century agriculture: Integration of plant microbiomes for improved crop production and food security. Microb. Biotechnol. 8:32-33.

Straub, C., Colombi, E., Li, L., Huang, H., Templeton, M. D., McCann, H. C., and Rainey, P. B. 2018. The ecological genetics of Pseudomonas syringae from kiwifruit leaves. Environ. Microbiol. 20:2066-2084.

The Huttenhower Lab. 2018. Department of Biostatistics. Harvard T.H., Boston, MA, U.S.A.

Toju, H., Peay, K. G., Yamamichi, M., Narisawa, K., Hiruma, K., Naito, K., Fukuda, S., Ushio, M., Nakaoka, S., Onoda, Y., Yoshida, K., Schlaeppi, K., Bai, Y., Sugiura, R., Ichihashi, Y., Minamisawa, K., and Kiers, E. T. 2018. Core microbiomes for sustainable agroecosystems. Nat. Plants 4:247-257.

Tontou, R., Gaggia, F., Baffoni, L., Devescovi, G., Venturi, V., Giovanardi, D., and Stefani, E. 2015. Molecular characterisation of an endophyte showing a strong antagonistic activity against Pseudomonas syringae pv. actinidiae. Plant Soil 405:97-106.

Tontou, R., Giovanardi, D., Michele, F., and Stefani, M. 2016. Isolation of bacterial endophytes from Actinidia chinensis and preliminary studies on their possible use as antagonists against Pseudomonas syringae pv. actinidiae. J. Berry Res. 6:395-406.

Turner, T. R., James, E. K., and Poole, P. S. 2013. The plant microbiome. Genome Biol. 14:209.

Vandenkoornhuyse, P., Quaiser, A., Duhamel, M., Le Van, A., and Dufresne, A. 2015. The importance of the microbiome of the plant holobiont. New Phytol. 206:1196-1206.

Vanneste, J. L. 2017. The scientific, economic, and social impacts of the New Zealand outbreak of bacterial canker of kiwifruit (Pseudomonas syringae pv. actinidiae). Annu. Rev. Phytopathol. 55:377-399.

Vorholt, J. 2012. Microbial life in the phyllosphere. Nat. Rev. Microbiol. 10:828-840.

Wagner, M., Lundberg, D., del Río, T., Tringe, S., Dangl, J., and MitchellOlds, T. 2016. Host genotype and age shape the leaf and root microbiomes of a wild perennial plant. Nat. Commun. 7:12151.

Wang, T., and Gleave, P. 2012. Applications of Biotechnology in kiwifruit (Actinidia). Pages 3-30 in: Innovation in Biotechnology. InterTech Open. https://www.intechopen.com/books/innovations-in-biotechnology/applicationsof-biotechnology-in-kiwifruit-actinidia-

Whipps, J. M., Hand, P., Pink, D., and Bending, G. D. 2008. Phyllosphere microbiology with special reference to diversity and plant genotype. J. Appl. Microbiol. 105:1744-1755.

White, D. C., Sutton, S. D., and Ringelberg, D. B. 1996. The genus Sphingomonas: Physiology and ecology. Curr. Opin. Biotechnol. 7:301306.

Wicaksono, A. W., Jones, E. E., Casonato, S., Monk, J., and Ridgway, H. J. 2018. Biological control of Pseudomonas syringae pv. actinidiae (Psa), the causal agent of bacterial canker of kiwifruit, using endophytic bacteria recovered from a medicinal plant. Biol. Control 116:103-112.

Woźniak, M., Gałązka, A., Grządziel, J., and Frąc, M. 2018. Microbial diversity of Paulownia spp. leaves-A new source of green manure. BioResources 13:4807-4819.

Yashiro, E., Spear, R. N., and MacManus, P. S. 2011. Culture-dependent and culture independent assessment of bacteria in the apple phyllosphere. J. Appl. Microbiol. 110:1284-1296. 